\title{
ARQUITETURA DE TREINAMENTO COLABORATIVO ${ }^{1}$
}

\section{COLLABORATIVE TRAINING ARCHITECTURE}

\author{
Jairit Garavit ${ }^{2}$ \\ https://orcid.org/0000-0003-1976-9891
}

1. ¿Este produto é o resultado do trabalho árduo de uma de suas Linhas de Pesquisa do projeto "Como deve pesquisar em Educação virtual e a distância?" do ano de 2021, realizada com Membros de forma interdisciplinar e interinstitucional (Professores - Alunos) da Pesquisa Seedbed: Sistemas Integrados de Gestão "Integradoss" Anexados ao GrupLAC: SIGCIENTY da Universidade Nacional Aberta e a Distância UNAD.

2. Engenheiro Industrial, Especialista em Educação Superior e à Distância, Mestre em Sistemas Integrados de Gestão HSEQ-RSC, Revisor de Pares da Elsevier, Revisor de Pares da Publons Academy e Advisor \& Peer Rewiever de Mendeley, Editor de Currículo em Revistas Acadêmicas - Minciencias. Líder da Seedbed de Pesquisa "Integradoss" e nomeado Professor Pesquisador da Escola de Ciências Básicas, Tecnologias e Engenharia ECBTI. Zona Caribenha, na Universidade Nacional Aberta e a Distância - UNAD. Email institucional Jairit.Garavit@unad.edu.co

Projeto de Pesquisa: ¿Cómo pesquisar em Educação virtual e a distância? 
Resumo: Argumentos iluministas na aprendizagem estão evoluindo eloqüentemente e, em meio a proteções e manobras construtivistas, o treinamento colaborativo é uma perspectiva de ensino cada vez mais exercitada. Este treinamento é uma visão grupal de aprendizagem que se baseia na inferência de que o conhecimento é um alicerce social, portanto, a arquitetura do conhecimento é um início social por meio do treinamento em grupo. As ilustrações da exploração dos elementos do treinamento colaborativo revelam extensões epistemológicas, sociais e veementes heterogêneas das cooperações de grupo. O que mais, A cooperação grupal desempenha um papel decisivo na consumação prática desta experiência académica e os professores frequentemente enfrentam a batalha dos contratempos no que diz respeito à textura e ao empenho dos grupos. Professores, em circunstâncias organizacionais para treinamento colaborativo, portanto, requerem revisão e avaliação da dinâmica de grupo. No entanto, pode haver diferentes marcos de quantificações de desempenho no nível geral e especificamente para examinar o ambiente de interações de grupo predominantes em um cenário de treinamento puramente colaborativo.

Palavras chave: Educação a distância, Treinamento colaborativo, Espaços comportamentais, Dinâmicas de grupo.

Abstract: Enlightenment arguments in learning are eloquently evolving and, amid constructivist protections and maneuvers, collaborative training is an increasingly exercised teaching perspective. This training is a group point of view of learning that is based on the inference that knowledge is a social foundation, therefore, the architecture of knowledge is a social start through group training. The illustrations of exploration on the elements of collaborative training reveal heterogeneous epistemological, social and vehement extensions of group cooperations. Furthermore, group cooperation plays a decisive role in the practical consummation of this academic experience, and teachers frequently take on the battle of setbacks concerning the texture and commitment of the groups. Teachers, in organizational circumstances for collaborative training, therefore, requires reviewing and evaluating group dynamics. However, there could be different milestones of performance quantifications both at the overall level and specifically to examine the environment of the predominant group interactions in a purely collaborative training scenario.

Keywords: Distance Education, Collaborative training, Behavioral spaces, Group Dynamics.

\section{Introdução}

Atualmente, os cursos universitários trazem em seu currículo aspectos como a exigência de avançar na aprendizagem de habilidades nos alunos em termos de trabalho em equipe, habilidades interpessoais e resolução de problemas. Por isso, na realização da programação educacional, a utilização de metodologias que incluam atividades que incentivem a cooperação ativa dos alunos pode ser de grande ajuda. A proposta de Grupos e Funções apresentada assenta 
nos princípios das metodologias ativas, em que educar se apropria de um papel ativo a favor da aprendizagem, promovendo um modelo que o estimule a refletir, analisar, tirar conclusões, etc. buscando seu envolvimento e comprometimento para tornar este processo mais formativo.

Até agora, vimos que a abordagem colaborativa se baseia em teorias sociocognitivas para defender um processo de reconstrução do conhecimento. Num contexto de aprendizagem à distância, apoiado num modelo colaborativo composto pela comunicação de ideias, coordenação e empenho, a formação colaborativa atualiza-se através da utilização de ambientes virtuais dispostos em espaços e lugares. Estratégias de interação em que os alunos têm uma variedade de recursos, ferramentas e meios para atingir o objetivo comum enquanto atendem às suas próprias expectativas e necessidades.

Neste capítulo, completamos nosso estudo descrevendo as fases de colaboração após analisar a dinâmica da interação cognitiva que ocorre entre quatro atores principais: o aluno, o grupo, o treinador e o especialista em conteúdo. Em seguida, passamos às habilidades cognitivas e colaborativas que o aluno deve dominar para participar plenamente do processo colaborativo. Em seguida, olhamos para o papel do formador que acompanha o aluno e cuja missão é ajudá-lo a progredir em seu caminho em direção a uma maior autonomia e maior responsabilidade por sua aprendizagem. Por fim, abordamos o problema da avaliação da aprendizagem, cuja complexidade é tão grande quanto a própria aprendizagem.

\section{Treinamento colaborativo e sua dinâmica cognitiva}

Segundo as teorias sociocognitivas, o treinamento resulta de interações sociais e cognitivas, como as que podem ser observadas entre o professor e o aluno. $\mathrm{O}$ aluno observa o professor, questiona-o, discute com ele e segue seus conselhos. O professor comenta, critica e corrige o trabalho do aluno; orienta e apresenta o seu know-how. De forma intencional e gradativa, disponibiliza ao aluno suas ferramentas, métodos e técnicas. Ao fazê-lo, o aluno toma consciência da relação que o professor tem com o seu meio e, aos poucos, vai descobrindo a utilidade social do trabalho do professor.

O aluno adquire a convicção de que o que aprende a fazer tem significado e abrangência. Reforçar o princípio da ancoragem social do conhecimento. Isso nos lembra, referindo-se às teorias sociais da aprendizagem de Piaget, Vygotsky e Leontiev, que o conhecimento só é verdadeiro se pudesse ser expresso, explicado, contextualizado e confrontado com outros. Boder (1993) também apóia esse princípio de ancoragem social, explicando que o conhecimento é apenas a informação que se tornará aprendizagem na ordem em que o aluno conseguir integrá-la de forma adequada.

Em um ambiente de aprendizagem, existem, portanto, quatro entidades que interagem: o ambiente como um agente de significado; o professor como especialista, possuidor de saberes e comunicador de saber socialmente reconhecido; o professor como formador, guia e acompanhante; e aprenda como um agente de sua própria mudança. Inicialmente, para o aluno, 
o conhecimento do professor, especialista em conteúdo, ainda é apenas "informação". Somente depois de aprender como usar a informação em um contexto realista e colocá-la em bom uso, o aluno será capaz de dizer que realmente aprendeu. (Garavit, J. 2020g)

O aluno consegue transformar a informação em conhecimento real e utilizável, na medida em que a vê como significado e significado social (Chou e Chan, 1995; Hannafin e Choi e, 1995). Isso significa, para ele, que entende a necessidade social que eles satisfazem e que realmente sabe como usá-los na realidade. Esse processo que leva à descoberta do sentido que deve ser dado à aprendizagem representa um grande desafio para o formador, principalmente quando se trata de conteúdos abstratos ou teóricos cuja aplicação em uso nem sempre é óbvia ou imediata. Este desafio é também do designer de ambientes virtuais e colaborativos de aprendizagem que deve imaginar não apenas um sistema de interações puramente cognitivas que favoreça a transformação da informação em conhecimento, mas também um sistema de interações humanas e sociais essenciais para o desenvolvimento de comunidades de aprendizagem. Para que a dinâmica cognitiva prospere dentro de um grupo, deve haver um clima social saudável repleto de motivação, um senso de pertencimento, compromisso e solidariedade. Portanto, o designer deve criar ambientes que envolvam os alunos e os levem ao compromisso com a aprendizagem e a construção conjunta de seus conhecimentos.

Nesses ambientes, dois sistemas de interação entram em jogo: o social e o cognitivo. Eles não são à prova d'água e influenciam uns aos outros. Sua química cada vez mais diferente significa que um grupo pode desenvolver sinergia e, assim, garantir que produza mais do que um indivíduo poderia fazer sozinho. Se aqui estamos fazendo o exercício de distinguir entre interações sociais e cognitivas, é porque, na midiatização de ambientes virtuais de aprendizagem, o designer deve vencer o cálculo dessas duas dimensões de colaboração para garantir um lugar justo para ambas. Sem minimizar a importância dos fatores humanos e sociais da aprendizagem (atitudes, motivação, clima social, cultura de grupo, etc.), continuamos nosso estudo nos limitando à descrição cognitiva dos quatro atores da aprendizagem e do sistema que os compõe.

\section{Atores de interação cognitiva}

A dinâmica cognitiva da aprendizagem reúne quatro atores que tentaremos localizar aqui. São eles 1) o modelo de conhecimento do especialista, 2) o aluno, 3) o grupo e 4) o formador que interage em uma dinâmica global convergente para a aprendizagem.

\section{O farol da noção especializada}

Em um ambiente de aprendizagem, o modelo de conhecimento é um corpus que representa o conhecimento socialmente reconhecido; É o objeto a saber, o objeto de estudo, o sujeito, o conteúdo de aprendizagem. É considerado trabalho do especialista. Nós o oferecemos como ator no processo de aprendizagem porque através dele é a sociedade que se expressa; porque influencia a sociedade e pode ser influenciado por ela. Um modelo de conhecimento não é uma 
entidade estável. Chamado a mudar de acordo com o avanço do conhecimento, do pensamento e da evolução da sociedade, ele reflete uma visão de mundo encarnada no tempo. Por meio dele, o especialista e, implicitamente, a sociedade propõe uma estrutura e uma organização do conhecimento que o aluno e o grupo, auxiliados pelo formador, irão explorar, apreender, criticar e reconstruir.

\section{O estudante}

Inicialmente, como já dissemos, o conhecimento do especialista permanece para o aluno apenas informações com as quais ele interage para compreender sua estrutura, abrangência, significado e utilidade. Num diálogo interno que mobiliza as suas capacidades de análise, síntese e pensador crítico, desenvolve as suas próprias representações. Esta primeira fase, que é de exploração, continua coletivamente com os membros do grupo. No espaço da comunicação, o aluno explicita suas primeiras construções cognitivas ao expressar suas ideias. Descubra modelos de conhecimento diferentes dos seus, dos seus colegas, membros do grupo. Seu modelo, mais ou menos elaborado, mais ou menos justo, será transformado, refeito e reconstruído ao longo de sua busca por informações, de sua reflexão pessoal e de suas interações com o grupo. As trocas entre o aluno e o grupo não são unilaterais; recebe, mas também dá.

\section{O grupo}

Das discussões e debates que acontecem entre os alunos durante a colaboração, emerge uma inteligência coletiva, uma entidade que tem existência própria. O grupo é uma entidade que nasce, cresce e se desenvolve por meio da interação de relacionamentos e interações entre seus membros. Você estabelece regras para si mesmo, inventa sua própria organização, distribui funções e trabalha em prol de um objetivo comum. Cada grupo desenvolve sua própria cultura e é caracterizado por seu grau de maturidade e engajamento cognitivo. A inteligência coletiva e os artefatos por ela produzidos permitem que ela desenvolva sua atividade. Em ambientes virtuais, o grupo, que forma um coletivo inteligente, se reúne para explorar e se apropriar do modelo de conhecimento do especialista. Durante as trocas e discussões, os membros compartilham informações, eles o estruturam e organizam de forma coerente e significativa para o grupo. As produções em grupo são mais do que um simples acúmulo de contribuições ou pontos de vista individuais; refletem um modelo de conhecimento organizado, original e diferente do especialista e de cada aluno.

\section{O professor, tutor e professor}

O Docente e o conhecimento especializado se confundem há muito tempo. O professor era o especialista e o conhecimento só era acessível por meio dele. Ele era seu dono, portador e comunicador. Ele estava desenvolvendo conhecimentos e cabia a ele ensiná-los. Hoje, essa concepção que transforma o treinador em professor vacila. A amplitude do conhecimento é tal que um treinador não pode mais ter tudo. Além disso, não pode mais competir com os meios de comunicação que tornam as informações acessíveis a todos de forma muito mais eficiente. 
A partir de agora, o conceito que funde "professor" e "saber especializado" perdeu o sentido, assim como a relação de autoridade que o caracterizava.

De acordo com o paradigma construtivista, o papel principal do formador não é transmitir conhecimentos; não é mais confundido com o corpo de conhecimento a ser adquirido. Ele é visto como um facilitador e facilitador da interação cognitiva e social. Sua função é, como explorador sábio, estruturar o processo de investigação e processamento da informação pelo aluno e pelo grupo. Acompanha-os, ajuda-os a dar sentido ao seu trabalho, incentiva, estimula e motiva-os. Ele zela pelo grupo, coleta informações sobre seu funcionamento, faz diagnósticos, formula hipóteses, desenvolve estratégias de intervenção e as implementa com os alunos e o grupo.

Figura 4.1

\section{Integração de informações em um aplicativo}

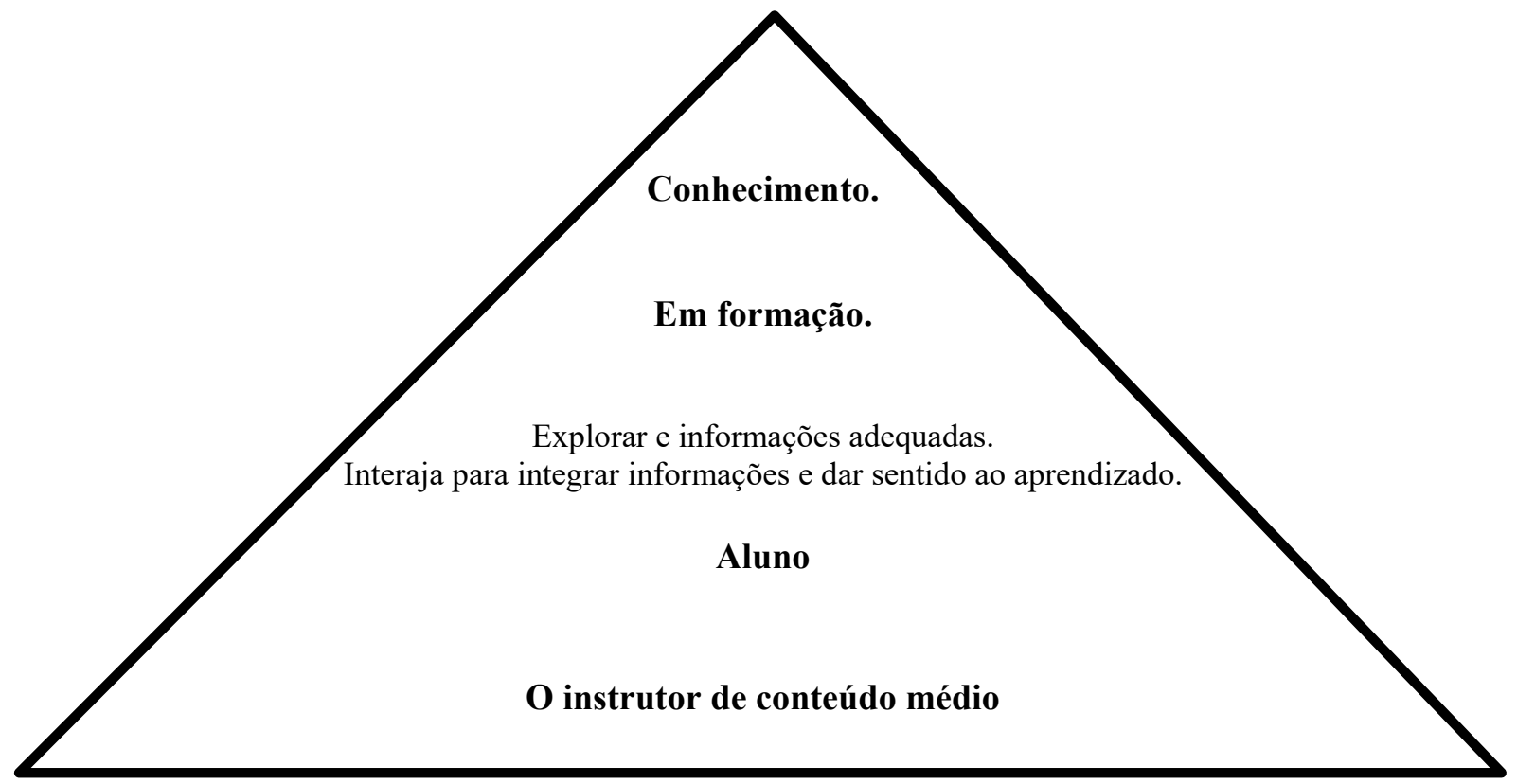

Garavit, J. 2021

Atua como um mediador entre as partes, preocupado com a produtividade cognitiva do grupo, mas também com o clima social que aí impera. A interação cognitiva que ocorre entre esses quatro atores é complexa, pois não segue um processo linear ou sequencial. Ele integra abordagens individuais e coletivas; Baseia-se na internalização e externalização de processos; é feito a partir da busca de significados e construções originais. Este é um sistema dinâmico de interações que tentamos representar na Figura 4.1.

Nessa dinâmica de aprendizagem cognitiva, o aluno, colocado em contato com o modelo de conhecimento do especialista, se engaja em um diálogo interno para forjar uma primeira representação do objeto a ser conhecido. Ao mesmo tempo, o grupo se baseia nas contribuições de outros e no modelo de conhecimento do especialista.

Dele extrai as informações de que precisa para fazer suas próprias construções, cumprir uma tarefa e conduzir a uma produção coletiva que carrega consigo um modelo original de 
conhecimento. $\mathrm{O}$ formador, por sua vez, apoia este processo oferecendo ao grupo e a cada aluno o seu apoio e ajuda na realização da tarefa e na construção do seu modelo de conhecimento. No final do processo, as construções cognitivas variam de um ator para outro.

Como mostra a Figura 4.2, eles são todos diferentes; os modelos de conhecimento do especialista, do aluno e do grupo não são exatamente os mesmos. Cada um desenvolveu sua própria estrutura cognitiva e distribuição das investigações adquiridas.

Figura 4.2

\section{Dinâmica cognitiva de treinamento colaborativo}

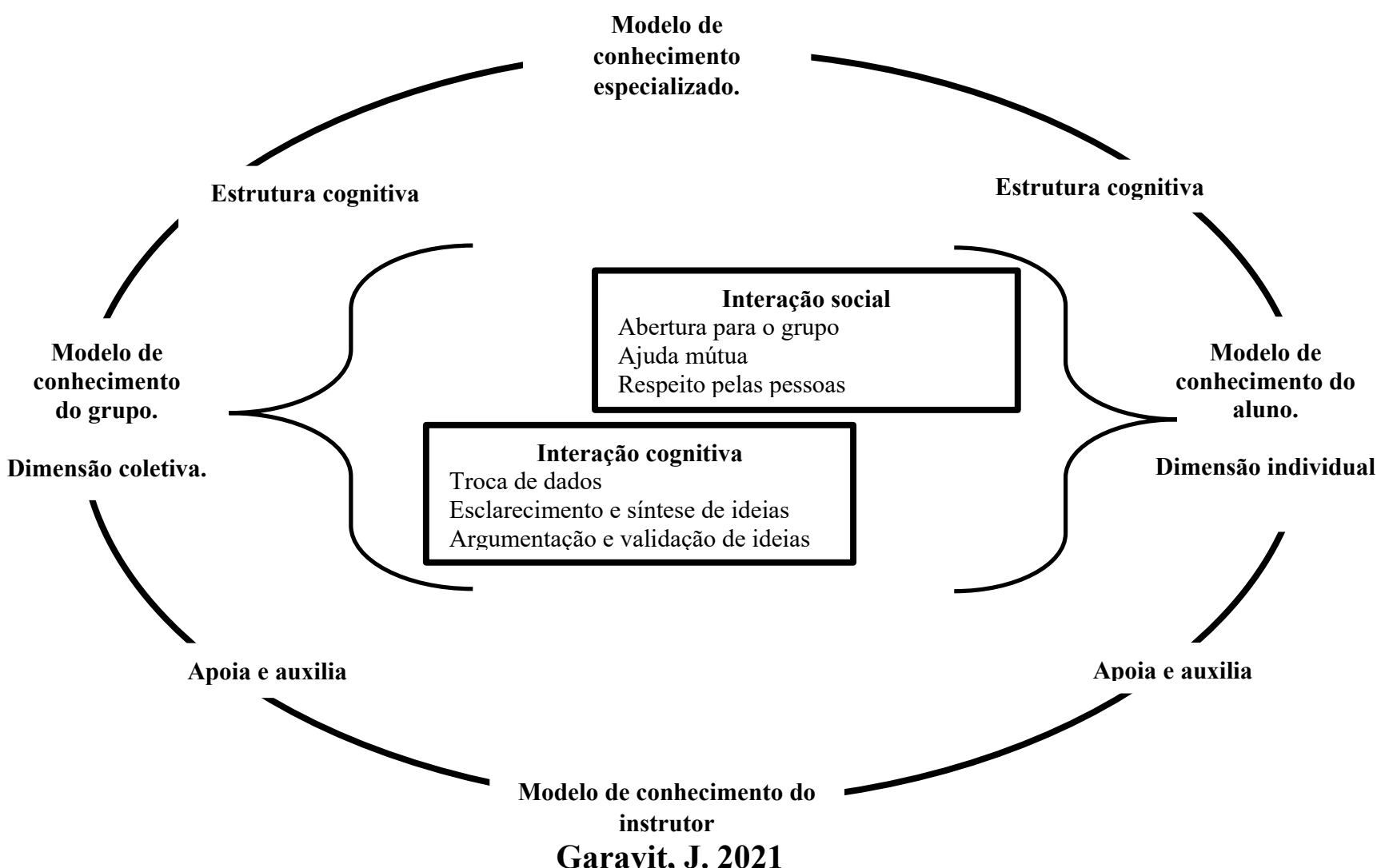

Garavit, J. 2021

\section{A direção da colaboração}

A dinâmica cognitiva que acabamos de descrever traduz uma visão ideal que queremos oferecer ao designer de ambientes virtuais de aprendizagem como um guia no avanço dos cenários de aprendizagem e no design de atividades educacionais. Compreender-se-á que esta dinâmica cognitiva se aplica à aprendizagem que aborda problemas e situações complexas, que promovem a interação, que requerem pensamento reflexivo, que mobilizam os recursos dos alunos e os levam a melhorarem. Nem sempre é fácil para o designer imaginar essas situações de aprendizagem. A fim de fornecer informações que facilitem sua tarefa, continuamos nossas pesquisas com análise colaborativa de processos para mostrar a dinâmica cognitiva em ação. 
Para marcar o processo colaborativo, propomos um processo em fases. Fazemos esta proposta com base em nossa experiência de colaboração no modo virtual e após ter estudado diferentes abordagens para a cooperação face a face, incluindo a proposta por Reid, Forrestal e Cook (1989). Eles desenvolveram um processo cooperativo de cinco etapas para jovens alunos: engajamento, exploração, transformação, apresentação e reflexão.

Esta abordagem não é adequada para colaboração entre alunos adultos ou para a realização de tarefas ou atividades no modo virtual. Em nossa experiência de trabalhar de forma assíncrona no modo virtual, um processo fragmentado com tantas etapas é trabalhoso, difícil de administrar e deixa muito pouco espaço e liberdade para o aluno. Na plataforma dos manuais de colaboração e dos princípios andragógicos apresentados nos capítulos anteriores, simplificamos a abordagem de Reid et al. reduzir o número de etapas para facilitar a coordenação, para dar mais flexibilidade e dar mais controle ao aluno. No processo colaborativo, encontramos três

destaques que não possuem prazos muito precisos. É por isso que falamos de uma evolução em fases que podem se sobrepor:

- Conhecimento e exploração do assunto que resulta em pesquisa e processamento inicial de informações.

- Ao mesmo tempo que se constrói o modelo de conhecimento do aluno, a negociação de ideias com vistas ao desenvolvimento pelo grupo de um modelo de conhecimento que reflita a pluralidade de pontos de vista.

- Reflexão pessoal e coletiva para avaliar ou avaliar modelos de conhecimento, dos alunos, do especialista e do grupo, e feedback sobre o processo colaborativo do grupo.

Cada uma dessas fases refere-se a um processo de trabalho individual e a um processo de trabalho em grupo que produz um resultado. Nós os descrevemos nas seções a seguir e os resumimos nas Tabelas 4.1 e 4.2 .

\section{Pesquisa de conhecimento}

Nesta primeira fase, o aluno explora o objeto a ser conhecido, decifra a informação que lhe é acessível e que pode ser considerada a instanciação do modelo de conhecimento do especialista. $\mathrm{O}$ aluno relaciona essas informações com o que sabe; eles os apreendem com suas estruturas cognitivas. Ao fazer isso, você avalia seu próprio conhecimento e seu escopo. A exploração é uma fase que visa definir o objeto a ser estudado em busca de informações, identificando conceitos e pontos de vista, e constitui uma primeira tentativa de compreensão e organização da informação. Leva o aluno a ordenar as informações que considera relevantes, abandonando o que considera desnecessário para o alcance do objetivo que persegue. Esta fase depende muito do trabalho individual que ocorre no espaço privado do aluno.

O cenário de treinamento incluirá tarefas ou atividades em grupo que permitem aos alunos formular várias questões relacionadas ao tópico ou área de aprendizagem; discutir estratégias e métodos para localizar, classificar, ordenar e dar uma estrutura inicial à informação. Essas 
atividades convidam os alunos a expressar livremente suas idéias por meio de, por exemplo, atividades de brainstorming, troca de informações, esclarecimento de idéias, discussão de estratégias para encontrar e recuperar informações, etc.

O resultado do trabalho, para o aluno e para o grupo, pode assumir várias formas: um esboço de mapa conceitual ou índice, um plano de trabalho, uma série de perguntas ou afirmações, uma declaração de posição, um ponto de vista, etc. A experiência muitas vezes nos permitiu observar uma participação muito forte dos alunos durante esta primeira fase da colaboração. $\mathrm{O}$ entusiasmo no início, a vontade de conhecer os outros e dar-se a conhecer, a necessidade de informação e orientação, bem como o carácter desestruturado das actividades explicam esta intensa actividade.

\section{Desenvolvimento de padrão de conhecimento}

Após o primeiro contato com o objeto a ser conhecido, o aprendiz, informado da tarefa a ser realizada, continua suas pesquisas e reflexões. Faça suas primeiras afirmações, desenvolva suas primeiras propostas ou seus primeiros pontos de vista. Nesta fase, as atividades são mais ou menos estruturadas, desenhadas de acordo com o grau de autonomia dos alunos. Isso pode incluir a realização de pesquisa documental, análise crítica, preparação para uma discussão, desenvolvimento de um resumo para as definições tomadas, trabalho na resolução de problemas, etc. Eles exigem que cada aluno explique suas ideias, desenvolva um raciocínio, construa um argumento suficientemente fundamentado e o compartilhe com seus colegas.

Paralelamente a essa atividade individual, o aluno responde e reage às propostas de seus colegas. Participa ativamente do trabalho do grupo que, como grupo, realiza sua própria tarefa, desenvolve sua própria construção, faz sua própria síntese. Por trás das conquistas do grupo, existe um modelo de conhecimento em torno do qual se constrói um consenso. Esse consenso não deve ser percebido como um gesto de renúncia ao modelo de conhecimento construído por cada um. Em vez disso, deve ser visto como um sinal de maturidade no grupo e nos participantes empenhados em alcançar o objetivo comum que estabeleceram para si próprios.

É então que o aluno aproveita ao máximo os recursos do seu pensamento criativo para fazer a sua própria síntese, comparar o seu modelo com o modelo coletivo, consolidá-lo e validá-lo. A convivência no ambiente de aprendizagem de vários modelos, o do especialista, o do grupo e o dos alunos, é apenas um reconhecimento de que o conhecimento não é igual para todos.

Convidados a não se apoiarem cegamente no que propõe o modelo de saber do especialista (saber socialmente constituído), a pensar por si mesmos com seus pares, a forjar sua própria construção e a participar daquele grupo, os alunos adotam um ritmo diferente de troca nesta fase de negociação e validação. Eles realizam intervenções mais longas e mais bem estruturadas. Comentários espontâneos e palavras impensadas não têm lugar.

Cada intervenção requer um verdadeiro investimento de tempo e energia, sendo o desafio transcender as posições individuais para atingir o objetivo comum. Os alunos devem ter tempo 
suficiente para participarem neste processo, para participarem na reflexão profunda e no desenvolvimento do pensamento holístico, que o designer do ambiente terá previsto. Além disso, as intervenções tranquilizadoras do formador irão convidá-lo a dedicar-se ao aprendizado, a uma postura crítica em relação à velocidade, competitividade, busca pela produtividade e desempenho excessivos, tantas vezes consagrados como valores em nossa sociedade tão antinomiano. classificada como sociedade do conhecimento.

\section{Avaliação do treinamento e as causas da colaboração}

A terceira fase é de reflexão sobre a aprendizagem individual e em grupo. Assume a forma de uma avaliação ou síntese de eventos, bem como de uma avaliação pelos alunos do sucesso da colaboração e coesão do grupo. Esta é uma oportunidade para que todos revisem seu modelo de conhecimento pela última vez. Antes de encerrar o processo de aprendizagem, esta reflexão serve para alimentar a avaliação que cada pessoa faz sobre sua autonomia e sua capacidade de aprender e colaborar para aprender. Esta fase visa permitir que os alunos compartilhem as dificuldades que podem ter experimentado durante a execução das tarefas, suas incertezas quanto à qualidade e eficiência de seu processo de aprendizagem e sua percepção de colaboração.

Tabela 4.1

Processos das fases da abordagem colaborativa

\begin{tabular}{|c|c|c|c|}
\hline \multirow{2}{*}{ Estágios } & \multicolumn{2}{|r|}{ Processo } & \multirow{2}{*}{ Resultados } \\
\hline & do estudante & do grupo & \\
\hline Exploração. & $\begin{array}{l}\text { Procurando informação. } \\
\text { Diálogo interno. } \\
\text { Julgamento sobre a } \\
\text { relevância e utilidade da } \\
\text { informação. }\end{array}$ & $\begin{array}{l}\text { Interação com colegas para } \\
\text { avançar na exploração de } \\
\text { o objeto de saber. } \\
\begin{array}{l}\text { Identificação de informações } \\
\text { relevantes e úteis. }\end{array}\end{array}$ & $\begin{array}{l}\text { Seleção de informações } \\
\text { relevantes e úteis. } \\
\text { Informações mais ou menos } \\
\text { estruturadas. } \\
\text { Planeje a continuação do } \\
\text { trabalho. }\end{array}$ \\
\hline $\begin{array}{l}\text { Elaboração. } \\
\text { Negociação. } \\
\text { Validação. }\end{array}$ & $\begin{array}{l}\text { Organização pessoal de } \\
\text { ideias, redação de um } \\
\text { modelo. } \\
\text { Feedback sobre seu } \\
\text { próprio modelo, } \\
\text { revisão, melhoria. } \\
\text { Consolidação } \\
\text { formalização do modelo } \\
\text { pessoal. }\end{array}$ & $\begin{array}{l}\text { Consideração das idéias e pontos } \\
\text { de vista dos outros. } \\
\text { Reação às ideias dos outros e } \\
\text { tentativa de estruturar } \\
\text { múltiplas contribuições. } \\
\text { Proposta de estrutura. } \\
\text { A posição de cada pessoa em } \\
\text { relação ao modelo de produção e } \\
\text { de grupo. } \\
\text { Conciliação, integração de pontos } \\
\text { de vista. }\end{array}$ & $\begin{array}{l}\text { Sucessivamente, por meio de } \\
\text { uma produção coletiva: } \\
\text { Várias propostas de modelos } \\
\text { de conhecimento. } \\
\text { Modelo de conhecimento do } \\
\text { grupo. } \\
\text { Consenso sobre o modelo de } \\
\text { produção e conhecimento de } \\
\text { grupo que reflete múltiplas } \\
\text { visões. }\end{array}$ \\
\hline Avaliação. & $\begin{array}{l}\text { Reflexão sobre } \\
\text { significado pessoal que } \\
\text { deve ser dado à } \\
\text { aprendizagem. } \\
\text { Avaliação das } \\
\text { estratégias } \\
\text { colaborativas utilizadas } \\
\text { e da contribuição para o } \\
\text { grupo. }\end{array}$ & $\begin{array}{l}\text { Reflexão sobre o sentido coletivo } \\
\text { que deve ser dado à aprendizagem } \\
\text { e sua utilidade social. } \\
\text { Avaliação do desempenho e } \\
\text { produtividade do grupo. }\end{array}$ & $\begin{array}{l}\text { Conscientização da utilidade } \\
\text { social das notícias } \\
\text { conhecimento. } \\
\text { Conscientização dos } \\
\text { requisitos e benefícios da } \\
\text { colaboração. }\end{array}$ \\
\hline
\end{tabular}

Garavit, J. 2021 
Muitas vezes pressionado pela falta de tempo no final do treinamento, o grupo pode ser tentado a condensar ou copiar esta fase. É por isso que o cenário de aprendizagem deve permitir um período de tempo suficiente e claramente identificado para realizar esta reflexão. $\mathrm{O}$ grupo deve ter e ter tempo para concluir e encerrar o aprendizado, caso contrário os alunos não poderão aprender com o processo colaborativo todas as aulas que deveriam. Nem serão capazes de se tornar mais cientes das demandas e benefícios da colaboração. $\mathrm{O}$ exercício de avaliação pode ser baseado em um blog que o grupo e os alunos foram solicitados a manter, uma análise das produções do grupo para as quais um sistema de arquivamento foi planejado,

\section{Síntese da perspectiva de colaboração}

Tabela 4.2

Componentes e fases do modelo colaborativo

\begin{tabular}{|c|c|c|c|}
\hline \multirow{2}{*}{$\begin{array}{c}\text { Fases de } \\
\text { colaboração }\end{array}$} & \multicolumn{3}{|c|}{ Componentes de colaboração } \\
\hline & Comunicação & Compromisso & Coordenação \\
\hline $\begin{array}{l}\text { Exploração - Fase } \\
\text { de } \\
\text { Comissionamento. } \\
\text { Ele permite que } \\
\text { você explore o } \\
\text { campo e faça } \\
\text { ligações entre } \\
\text { ideias expressas. } \\
\text { Acima de tudo, visa } \\
\text { fazer uma escolha } \\
\text { crítica } \\
\text { informação } \\
\text { (relevância } \\
\text { utilidade). }\end{array}$ & 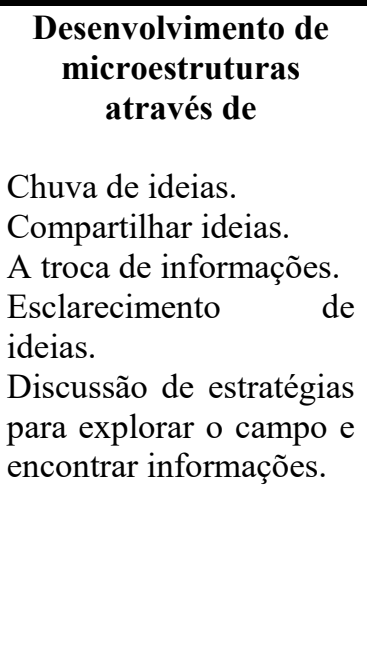 & $\begin{array}{l}\text { Compromisso social } \\
\text { Conscientização do objetivo } \\
\text { comum e expressão de } \\
\text { interesses e objetivos pessoais, } \\
\text { Formulação das expectativas de } \\
\text { todos em relação ao grupo, } \\
\text { Primeiro estágio no } \\
\text { desenvolvimento de uma } \\
\text { comunidade estudantil, } \\
\text { Conscientização } \\
\text { importância da participação. } \\
\text { Engajamento cognitivo } \\
\text { Consenso sobre o objetivo, } \\
\text { Método de trabalho em grupo, } \\
\text { Resultados antecipados. }\end{array}$ & $\begin{array}{l}\text { Organização do } \\
\text { Trabalho } \\
\text { Reconhecimento da } \\
\text { arquitetura do ambiente } \\
\text { virtual, incluindo locais } \\
\text { de comunicação, } \\
\text { Consolidação de equipe, } \\
\text { Estabelecimento de um } \\
\text { plano de trabalho, } \\
\text { Orientação cognitiva } \\
\text { para o trabalho, } \\
\text { Desenvolvimento de um } \\
\text { consenso sobre as } \\
\text { modalidades de } \\
\text { colaboração. }\end{array}$ \\
\hline
\end{tabular}

Garavit, J. 2021.

Como conclusão desta seção, resumimos o processo colaborativo na Tabela 4.1, dando para cada uma das fases as principais características do processo individual e do processo grupal e indicando os resultados. Na Tabela 4.2, completamos esta síntese revisando as três fases da colaboração, ou seja, exploração, desenvolvimento e avaliação, e relacionando-as aos três componentes básicos da colaboração: comunicação, engajamento e coordenação. 
Tabela 4.2

Componentes e fases do modelo colaborativo (continuação)

\begin{tabular}{|c|c|c|c|}
\hline \multirow{2}{*}{ Fases de colaboração } & \multicolumn{3}{|c|}{ Componentes de colaboração } \\
\hline & Comunicação & Compromisso & Coordenação \\
\hline \begin{tabular}{l}
\multicolumn{1}{c}{$\begin{array}{c}\text { Construção do } \\
\text { conhecimento. }\end{array}$} \\
Fase culminante. \\
Vamos expandir \\
interdependência positiva \\
dentro do grupo. \\
Seu objetivo é a construção \\
coletiva de um modelo de \\
conhecimento por meio de \\
transação e validação.
\end{tabular} & $\begin{array}{l}\text { Participação em trocas: } \\
\text { Posições tomadas, } \\
\text { Agradecimento } \\
\text { feedback. } \\
\text { Desenvolvimento de } \\
\text { macroestruturas como: } \\
\text { Análise crítica. } \\
\text { O debate. } \\
\text { Decisões tomadas } \\
\text { Resolução } \\
\text { problemas. }\end{array}$ & $\begin{array}{l}\text { Participação regular e } \\
\text { voluntária. } \\
\text { Conscientização da } \\
\text { predominância do } \\
\text { objetivo comum e do } \\
\text { processo colaborativo. } \\
\text { Transcendência de } \\
\text { interesses individuais } \\
\text { para refletir os do } \\
\text { grupo. }\end{array}$ & $\begin{array}{l}\text { Escolha de um método } \\
\text { de animação e um } \\
\text { facilitador. } \\
\text { Decisões relacionadas } \\
\text { com o arquivo de } \\
\text { informações (públicas, } \\
\text { privadas) e a troca de } \\
\text { recursos (grau de troca). } \\
\text { Gerenciando trabalhos } \\
\text { individuais e em grupo e } \\
\text { monitorando seu } \\
\text { progresso. }\end{array}$ \\
\hline $\begin{array}{l}\text { Avaliação } \\
\text { Fase de reflexão } \\
\text { Permite ao aluno consolidar } \\
\text { os seus conhecimentos, rever } \\
\text { o processo de colaboração e } \\
\text { as suas competências nesta } \\
\text { área. } \\
\text { Seu objetivo é reconhecer o } \\
\text { significado de aprender sobre } \\
\text { o objeto a ser conhecido e } \\
\text { sobre a colaboração. }\end{array}$ & $\begin{array}{l}\text { Revisão do exercício } \\
\text { colaborativo e dos } \\
\text { conhecimentos } \\
\text { adquiridos. } \\
\text { Avaliação da eficácia } \\
\text { das construções de } \\
\text { grupo }\end{array}$ & $\begin{array}{l}\text { Avaliação da coesão e } \\
\text { produtividade do } \\
\text { grupo. }\end{array}$ & $\begin{array}{l}\text { Avaliação do modelo e } \\
\text { métodos de colaboração. } \\
\text { Lições para aprender. }\end{array}$ \\
\hline
\end{tabular}

\section{Habilidades de aprendizagem cognitiva}

Em cada fase da colaboração, a dinâmica cognitiva que desejamos ver estabelecida dentro do grupo requer que o aluno incorpore experiências cognitivas de alto nível que associamos ao pensamento reflexivo, como Pallascio e Lafortune (2000) descrevem. O pensamento reflexivo é uma construção que gira em torno do pensamento crítico e criativo, habilidades de argumentação e habilidades metacognitivas.

Para esses autores, cada um desses níveis de pensamento é detalhado a seguir:

- O pensamento crítico permite distinguir, em um determinado contexto, as informações mais relevantes para o objetivo perseguido.

- O pensamento criativo visa o surgimento de sínteses originais

- E com sucesso.

- As habilidades argumentativas suportam a expressão do pensamento reflexivo, o conhecimento dos argumentos que podem compartilhá-lo e mostrar seu rigor e mérito.

- Metacognição refere-se a um conjunto de conhecimentos que cada pessoa possui sobre seu próprio processo cognitivo e o uso desse conhecimento para gerenciar seus processos mentais. 
O pensamento reflexivo fornece flexibilidade e liberdade intelectual que ajuda as pessoas a exercerem sua agência e contribui para a realização cognitiva e social. Não podemos imaginar que todos os alunos tenham habilidades de pensamento reflexivo desde o início; eles devem ser cultivados. De acordo com Daniel et al. (2000), a cooperação e, em nossa opinião, a colaboração poderia ajudar a desenvolvê-los.

Para promover o desenvolvimento do pensamento reflexivo no aluno, ele deve ser capaz de reconhecê-lo. De acordo com Baffrey-Dumont (2000), resulta no uso de julgamentos reflexivos que podem ser distinguidos de julgamentos pré-reflexivos e quase-reflexivos. Este autor define esses três tipos de julgamentos da seguinte forma:

- O preconceito flexional se expressa quando o sujeito acredita que o conhecimento é absolutamente correto e verdadeiro.

- O julgamento quase reflexivo é o fato de os sujeitos o reconhecerem.Parece que as afirmações sobre o conhecimento contêm elementos de incerteza.

- O julgamento reflexivo é observado em sujeitos que consideram o conhecimento como provisório e evolutivo; que são capazes de levar em conta múltiplos quadros de referência, incluindo suas contradições; que saibam integrar os elementos do contexto para chegar a uma síntese em uma unidade mais integrada. No momento dessa integração, o sujeito constrói seu conhecimento se comprometendo com determinados valores, aderindo a crenças e dando lugar à subjetividade.

O formador que acompanha os alunos deve ser capaz de identificar a presença desses julgamentos e desenvolver as estratégias consequentes para favorecer aqueles que refletem o pensamento reflexivo. O designer que desenvolve o ambiente deve, por sua vez, integrar condições e apoios para ajudar os alunos a se prepararem e aprenderem a discernir. As condições propostas por Martineau (2000) serão levadas em consideração para quem aprende a pensar:

- Deve ser um objetivo explícito.

- Deve ser feito em um contexto significativo.

- É facilitado por um contexto de interação social.

- Requer muitas oportunidades de prática.

- Facilitado pelo treinamento em metacognição.

- Uma preocupação com a transferência.

Baffrey-Dumont observou que as formulações correspondentes aos três tipos de julgamento reflexivo, quase reflexivo e pré-reflexivo podem coexistir na fala de um indivíduo. No entanto, ele aponta que o nível de julgamento reflexivo só se manifesta se os níveis pré-reflexivo e quase-reflexivo tiverem sido adquiridos. Portanto, devemos encorajar aqueles que são capazes de julgar reflexivos a se empenharem sempre e trabalharem com os outros para aprender a pensar e ir além dos níveis pré-reflexivo e quase-reflexivo. 
Embora um bom número de educadores e treinadores concorde que aprender a pensar envolve o desenvolvimento de habilidades cognitivas e metacognitivas, queremos relatar aqui a reflexão de Romainville (2000) sobre metacognição. Este autor desafia a suposição amplamente compartilhada pela atual exploração educacional e experiência de que o avanço da metacognição é uma das representações excelentes do desenvolvimento da validade cognitiva dos alunos. Em sua análise crítica, ele observa que a reflexão sobre o ato de aprender pode dificultar o próprio ato de aprender, distraindo-o.

O tiro pode sair pela culatra. Corre-se o risco de abrandar a ação ou mesmo interromper a sua execução se, durante a execução da tarefa, o aluno for solicitado a perceber como funciona. seus próprios processos de pensamento e seus próprios esforços para compreendê-los e gerenciá-los. O treinamento em metacognição deve ser realizado de forma gradual, no âmbito de atividades específicas.

O que Romainville quer enfatizar é o fato de que a metacognição deve ser utilizada no momento certo e para a situação certa de aprendizagem.

Tabela 4.3

Pensamento reflexivo e as fases de colaboração

\begin{tabular}{|c|c|c|c|c|}
\hline \multirow{2}{*}{$\begin{array}{c}\text { Fases de } \\
\text { colaboração }\end{array}$} & \multicolumn{4}{|c|}{ Possibilidade de colocar texto nos fóruns de } \\
\hline & pensamento critico & $\begin{array}{l}\text { pensamento } \\
\text { criativo }\end{array}$ & o argumento & metacognição \\
\hline $\begin{array}{l}\text { Exploração } \\
\text { Preparação } \\
\text { Buscador. } \\
\text { Informante. } \\
\text { Designer de novas } \\
\text { ideias. }\end{array}$ & $\begin{array}{l}\text { Buscar informação. } \\
\text { Identifique e } \\
\text { compreenda ideias } \\
\text { Escolha as } \\
\text { informações } \\
\text { relevantes. }\end{array}$ & 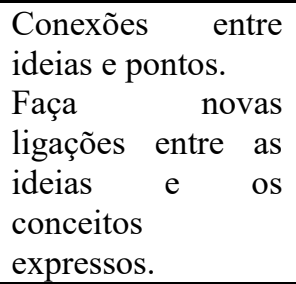 & \multirow{2}{*}{$\begin{array}{l}\text { Exposer são point } \\
\text { de } \\
\text { voar em faisant } \\
\text { des } \\
\text { demonstrações } \\
\text { provável. } \\
\text { Réfuter } \\
\text { arguments. des } \\
\text { Reconnaître la } \\
\text { justesse } \\
\text { de } \\
\text { l'argumentation. }\end{array}$} & $\begin{array}{l}\text { Melhore sua pesquisa } \\
\text { Procure métodos de } \\
\text { trabalho eficientes. } \\
\text { Fornece um ambiente } \\
\text { de trabalho. } \\
\text { Faça um plano. }\end{array}$ \\
\hline $\begin{array}{l}\text { A elaboração } \\
\text { - negociação } \\
\text { Funções do aluno: } \\
\text { cognitivo, } \\
\text { Apresentador. } \\
\text { Debatedor. } \\
\text { Advogado. } \\
\text { Juiz. }\end{array}$ & $\begin{array}{l}\text { Extrai a estrutura e } \\
\text { os princípios do } \\
\text { domínio. } \\
\text { Discuta pontos de } \\
\text { vista. } \\
\text { Compare, analise e } \\
\text { avalie as opiniões. } \\
\text { Emita um } \\
\text { julgamento de } \\
\text { conhecimento }\end{array}$ & $\begin{array}{l}\text { Reconstruir, } \\
\text { propondo uma } \\
\text { nova integração de } \\
\text { em formação. } \\
\text { Faça concessões. } \\
\text { Reconcilie as } \\
\text { diferenças para } \\
\text { chegar a um } \\
\text { consenso. }\end{array}$ & & $\begin{array}{l}\text { Considere suas } \\
\text { próprias abordagens e } \\
\text { as do grupo. } \\
\text { Reconheça e respeite } \\
\text { os ritmos e diferenças } \\
\text { dos outros. }\end{array}$ \\
\hline
\end{tabular}

Garavit, J. 2021

Ao final, apresentamos um quadro-resumo que mostra como as habilidades de pensamento reflexivo podem ser expressas por meio das três fases de colaboração e os vários papéis que podem ser oferecidos aos alunos para promover seu desenvolvimento. Às quatro grandes habilidades de Pallascio e Lafortune (2000), adicionamos a habilidade de escrever um discurso que está relacionado ao pensamento crítico e criativo, argumentação e metacognição. É uma habilidade transversal que nos parece importante e que não deve ser negligenciada, uma vez que alunos que evoluem em ambientes virtuais se engajam em comunicação essencialmente 
textual. Neste contexto, a aquisição de know-how através da escrita parece-nos essencial para que a colaboração seja eficaz.

Tabela 4.3

O pensamento reflexivo e as fases de colaboração (continuação)

\begin{tabular}{|c|c|c|c|c|}
\hline \multirow{2}{*}{$\begin{array}{l}\text { Fases de } \\
\text { colaboração }\end{array}$} & \multicolumn{4}{|c|}{ Possibilidade de colocar texto nos fóruns de ... } \\
\hline & pensamento critico & $\begin{array}{c}\text { pensamento } \\
\text { criativo }\end{array}$ & o argumento & metacognição \\
\hline $\begin{array}{l}\text { Validação } \\
\text { Funções: } \\
\text { Analista. } \\
\text { Tomador de } \\
\text { Decisão. }\end{array}$ & $\begin{array}{l}\text { Aceitar propostas } \\
\text { julgadas e válidas }\end{array}$ & \multirow{2}{*}{$\begin{array}{l}\text { Resuma toda a } \\
\text { experiência } \\
\text { formulando uma } \\
\text { avaliação da } \\
\text { coesão } \\
\text { produtividade do } \\
\text { grupo. }\end{array}$} & \multirow[b]{2}{*}{$\begin{array}{l}\text { Saiba como } \\
\text { equilibrar } \\
\text { conhecimento e } \\
\text { processos } \\
\text { colaborativos. }\end{array}$} & $\begin{array}{l}\text { Início da transferência: } \\
\text { consciência das } \\
\text { diferenças e formas de } \\
\text { adaptar o conhecimento } \\
\text { a outros contextos. }\end{array}$ \\
\hline $\begin{array}{l}\text { Avaliação. } \\
\text { Reflexão } \\
\text { Funções: } \\
\text { Filósofo. } \\
\text { Juiz. }\end{array}$ & $\begin{array}{l}\text { Provas de pista } \\
\text { da experiência de } \\
\text { aprendizagem. } \\
\text { Faça } \\
\text { construtivas } \\
\text { comparaçóticas } \\
\text { O modelo de } \\
\text { conhecimento do grupo }\end{array}$ & & & $\begin{array}{l}\text { Faça um balanço das } \\
\text { posições ou pontos de } \\
\text { vista. } \\
\text { Julgue sua própria } \\
\text { contribuição. } \\
\text { Avalie suas habilidades. }\end{array}$ \\
\hline
\end{tabular}

Garavit, J. 2021

\section{A assimilação da colaboração}

Se podemos dizer que a colaboração é uma situação propícia para aprender a pensar, não devemos perder de vista que a colaboração, especialmente no modo virtual, é também um exercício que pode ser aprendido. Saber colaborar não é inato: pode ser aprendido, assim como conhecimentos ou habilidades disciplinares. Saber colaborar requer habilidades cognitivas e metacognitivas, além de habilidades sociais, atitudes psicológicas e disposições afetivas. Para colaborar, os alunos devem estar preparados para isso.

Eles devem estar dispostos a se comprometer, ser capazes de assumir a responsabilidade por seu aprendizado, abertos aos outros e motivados a participar ativamente do trabalho do grupo. Caso contrário, eles devem estar preparados para isso. Nesse sentido, o designer do ambiente de aprendizagem e o treinador têm funções e responsabilidades específicas. O designer deve propor ao treinador estratégias e procedimentos de intervenção que tenham como objetivo explícito o desenvolvimento de habilidades de colaboração. $\mathrm{O}$ formador deve saber fazer um diagnóstico dessas competências, escolher entre as abordagens de intervenção que lhe são oferecidas mais adequadas e, se necessário, saber adaptá-las.

Colaborar não é um exercício abstrato, é um gesto concreto. Portanto, aprender a colaborar não deve se limitar a saber o que fazer sem realmente poder fazê-lo. A conceituação de colaboração deve ser mobilizada para a ação e esta ação deve ser eficaz. Como Lundgren (1996) sugere, aprender a colaborar, especialmente com alunos que são novos em suas experiências, começa com a negociação em grupo do modelo de colaboração e das modalidades que serão aplicadas para realizar a atividade de treinamento. Esta atividade preparatória leva o grupo a 
estabelecer um objetivo comum, comprometer-se a alcançá-lo e desenvolver uma percepção positiva de colaboração.

\section{Acordo de modelo de colaboração de grupo}

O fórum de telegestão é o lugar ideal para negociar o modelo de colaboração que vai reger a atividade do grupo. Esta atividade deve ser orientada e rigorosamente supervisionada pelo formador, principalmente se o grupo está em suas primeiras experiências de colaboração em um ambiente virtual. Cabe principalmente ao grupo descobrir, compreender e avaliar suas necessidades e, em seguida, definir como a colaboração funcionará e como as tarefas serão realizadas. Este exercício não é teórico; permite traduzir, em termos práticos, expectativas e percepções e estabelecer um consenso sobre o que os alunos farão no e com o grupo. O modelo de colaboração negociado pelo grupo no início do treinamento pode ser constantemente revisado e renegociado.

Desde o início da formação, o formador explica agrupando, de forma explícita e específica, o funcionamento que vislumbra e os requisitos do processo de aprendizagem que se propõe. $\mathrm{O}$ grupo então analisa o modelo de colaboração proposto e avalia sua relevância em relação às suas necessidades e benefícios que dele derivam. Uma discussão leva a uma tomada de decisão coletiva sobre as regras que regerão a atividade individual e em grupo.

A colaboração deve ser vista positivamente pelos membros do grupo e agregar valor ao aprendizado do qual participarão. Tendo isto em conta, irão negociar entre si e com o formador os termos da colaboração: participação (ritmo, frequência, âmbito das intervenções), trabalho em equipa, natureza das contribuições de cada um, parâmetros ou características das produções ou equipamentos do grupo, horas de trabalho e quaisquer outras disposições adequadas. Esse trabalho iniciado no início do treinamento deve resultar em uma representação comum e compartilhada da colaboração, um acordo sobre o que cada um está disposto a dar e o que ganhará. No entanto, os termos e regras de colaboração podem ser questionados a qualquer momento durante o curso da atividade de treinamento.

O modelo pode ser modificado para, por exemplo, ajudar o grupo a ser mais eficiente, promover melhor coesão, fazer com que o modelo se ajuste melhor ao que os membros esperam da colaboração, etc. A Tabela 4.4 resume o processo de negociação em andamento. 
Tabela 4.4

Processo de negociação do modelo

\begin{tabular}{|c|c|c|c|}
\hline $\begin{array}{l}\text { Estágios de } \\
\text { treinamento }\end{array}$ & Aluno & Grupo & Anterior \\
\hline $\begin{array}{l}\text { Inicio do treino } \\
\text { Objetivo: chegar a um } \\
\text { acordo sobre um } \\
\text { modelo colaborativo. }\end{array}$ & $\begin{array}{l}\text { Expresse suas } \\
\text { percepções, } \\
\text { expectativas } \\
\text { necessidades. } \\
\text { quando se trata de } \\
\text { colaboração. } \\
\text { Indica a contribuição e } \\
\text { o esforço colaborativo } \\
\text { que você está disposto } \\
\text { a oferecer. }\end{array}$ & 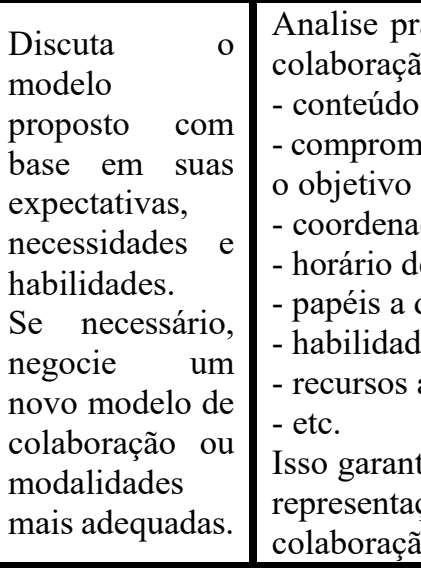 & $\begin{array}{l}\text { maticamente o modelo de } \\
\text { oroposto: } \\
\text { ritmo de comunicação, } \\
\text { o com o grupo para atingir } \\
\text { mum, } \\
\text { o da tarefa a ser realizada, } \\
\text { rabalho, } \\
\text { sempenhar, } \\
\text { para demonstrar, } \\
\text { erem usados, } \\
\text { que os alunos tenham uma } \\
\text { comum e consensual da }\end{array}$ \\
\hline $\begin{array}{l}\text { Treinamento } \\
\text { Objetivo: otimizar a } \\
\text { colaboração. }\end{array}$ & 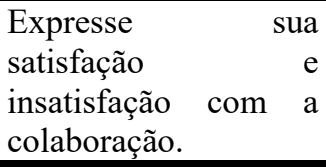 & $\begin{array}{l}\text { Valorize sua produtividade. } \\
\text { Se necessário, proponha } \\
\text { ajustes ao modelo de } \\
\text { colaboração. }\end{array}$ & $\begin{array}{l}\text { Faça uma avaliação } \\
\text { formativa de como } \\
\text { funciona a colaboração. }\end{array}$ \\
\hline $\begin{array}{c}\text { No final do } \\
\text { treinamento } \\
\text { Objetivo: perceber que } \\
\text { a colaboração é uma } \\
\text { experiência de } \\
\text { aprendizagem. }\end{array}$ & $\begin{array}{l}\text { Dê uma olhada no } \\
\text { processo colaborativo. } \\
\text { Identifique } \\
\text { competências } \\
\text { adquiridas e as que } \\
\text { ainda faltam em } \\
\text { termos } \\
\text { colaboração. }\end{array}$ & $\begin{array}{l}\text { Dê uma olhada no processo } \\
\text { colaborativo. } \\
\text { Avalie a produtividade do } \\
\text { grupo e os resultados } \\
\text { obtidos. }\end{array}$ & $\begin{array}{l}\text { Avalia a colaboração em } \\
\text { relação ao seu objeto, } \\
\text { finalidade } \\
\text { funcionamento. }\end{array}$ \\
\hline
\end{tabular}

Garavit, J. 2021

Além de usar atividades formais para preparar e estabelecer colaboração, aprender a colaborar é feito observando o treinador que deve dar o exemplo com suas ações e discurso. Você demonstrará a habilidade de compartilhar e a habilidade de se abrir para os outros e as idéias dos outros, a habilidade de negociar e a habilidade de reconciliar seus pensamentos com os dos outros. O treinador também transmitirá a mensagem de que a liderança é essencial para a colaboração. Para desenvolver a liderança, Tagg (1994) sugere gradualmente atribuir aos alunos a responsabilidade de liderar suas próprias trocas de facilitadores. A função do formador consistirá então simplesmente em apoiá-los na sua animação. Desta forma, os alunos serão forçados a tomar decisões,

A Figura 4.3 apresenta a curva de crescimento ideal para o controle que o aluno exerce sobre sua aprendizagem e o ganho de autonomia ao longo do processo de treinamento. 
Figura 4.3

Desenvolvimento do aluno

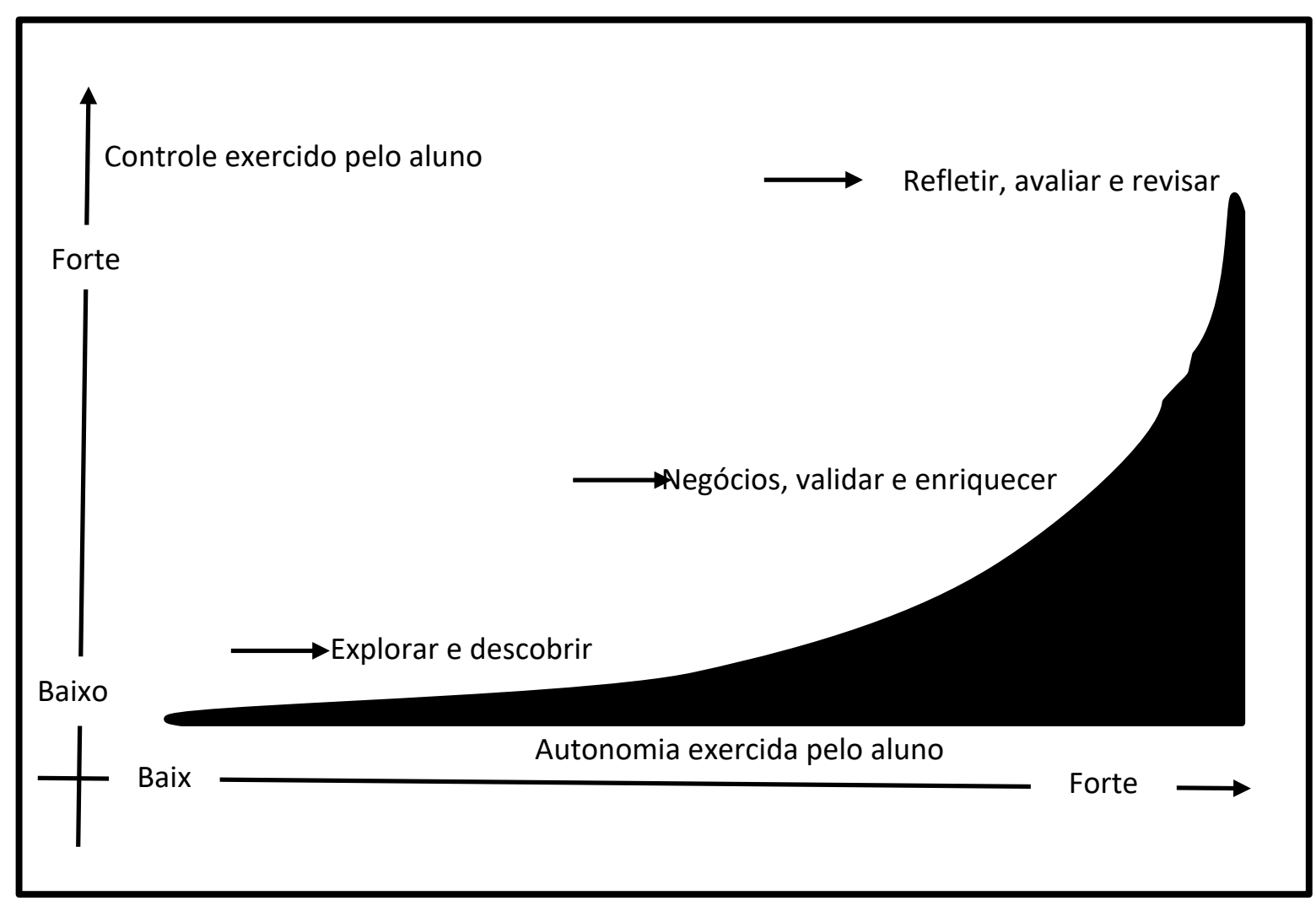

Garavit, J. 2021

\section{Construção de Conhecimento}

$\mathrm{Na}$ abordagem colaborativa, o treinador atua no apoio à aprendizagem. É um guia cujo papel evolui à medida que o aluno adquire mais autonomia e assuma mais responsabilidade pela sua aprendizagem.

\section{Funções do treinador}

Vários autores descreveram as múltiplas facetas do papel do treinador no treinamento a distância (Damphousse, 1996). É ele quem aconselha, orienta, ajuda a compreender os conteúdos da aprendizagem, organiza e incentiva grupos e equipas e avalia o trabalho dos alunos. Intervém individualmente com os alunos para esclarecer o conteúdo da aprendizagem, oferecer-lhes métodos de trabalho intelectual e sugerir a aplicação de estratégias eficazes. Sua função é essencialmente facilitar a aquisição de conhecimento (Feenberg, 1989). Em ambientes colaborativos virtuais, o formador se manifesta e intervém sobretudo em fóruns de discussão. Como em uma situação de colaboração pré-existente, ela satisfaz as necessidades do grupo, encoraja e encoraja trocas, encoraja a participação de todos, estimula as interações e garante o 
bom desenvolvimento do trabalho. Sua missão é ajudar o grupo a progredir em direção ao objetivo comum da maneira mais eficaz possível.

Ricciardi Rigault et al. (1993) e Damphousse (1996) mostraram que, no contexto dos fóruns de discussão, o treinador não deve assumir várias funções ao mesmo tempo. Em locais de telediscussão, você modera as discussões e pode tratar o objeto de aprendizagem como um especialista em conteúdo faria. Nos locais de teletrabalho, o formador ajuda os formandos a encarregar-se da sua facilitação e a gerir o seu trabalho em equipa; em seguida, desempenhe o papel de treinador. Na telegestão, ele se torna um gestor educacional e cuida da organização da aprendizagem. Dê lugar ao outro, seu papel se distingue. Ao exercer essas várias funções e ao longo da colaboração, você será solicitado a modular suas intervenções de acordo com o progresso do grupo.

Tabela 4.5

Intervenções do treinador e aquisição de conhecimento

\begin{tabular}{|c|l|}
\hline $\begin{array}{c}\text { Intervenções nas três } \\
\text { fases }\end{array}$ & \multicolumn{1}{c|}{ Exemplos de intervenção } \\
\hline $\begin{array}{c}\text { Moderador } \\
\text { Fase de exploração }\end{array}$ & $\begin{array}{l}\text { - Apresentar o objeto a ser conhecido (estrutura e modelo de conhecimento), sugerir } \\
\text { estratégias cognitivas de recuperação da informação, propor métodos de trabalho. } \\
\text { - Faça conexões entre ideias e conceitos. } \\
\text { - Assegurar o estabelecimento de regras de colaboração. }\end{array}$ \\
\hline $\begin{array}{c}\text { Facilitador } \\
\text { Fase de } \\
\text { desenvolvimento }\end{array}$ & $\begin{array}{l}\text { - Apoiar e estimular o desenvolvimento do conhecimento, prestar esclarecimentos } \\
\text { sobre o objeto de conhecimento, sugerir formas de aprender e trabalhar. } \\
\text { - Auxiliar o grupo na negociação e validação do Conhecimento. }\end{array}$ \\
\hline $\begin{array}{c}\text { Animador } \\
\text { Fase de avaliação }\end{array}$ & $\begin{array}{l}\text { - Intervir a pedido dos alunos, atitude sensível. } \\
\text { - Se necessário, incentive a reflexão e o feedback para melhorar a compreensão. }\end{array}$ \\
\hline $\begin{array}{c}\text { Avaliador } \\
\text { Em todas as fases foi aprendido. }\end{array}$ & $\begin{array}{l}\text { - Avaliar o funcionamento do grupo (clima, coesão, produtividade) e planear as } \\
\text { intervenções em conformidade. } \\
\text { - Especifique os critérios de avaliação da aprendizagem e a forma de pontuação. }\end{array}$ \\
\hline - Avalie as produções cognitivas.
\end{tabular}

Garavit, J. 2021

\section{Intervenções específicas de colaboração}

Em cada fase da colaboração, as intervenções do formador mudam com a evolução dos próprios alunos, que vão se tornando cada vez mais autônomos e cada vez mais aptos a colaborar. Durante a fase de exploração, o treinador é o moderador, sua supervisão fica mais próxima. $\mathrm{Na}$ fase de desenvolvimento do conhecimento, atua como um facilitador. E, por fim, atuará como um simples facilitador na fase de avaliação. 
Figura 4.4

De moderador a animador

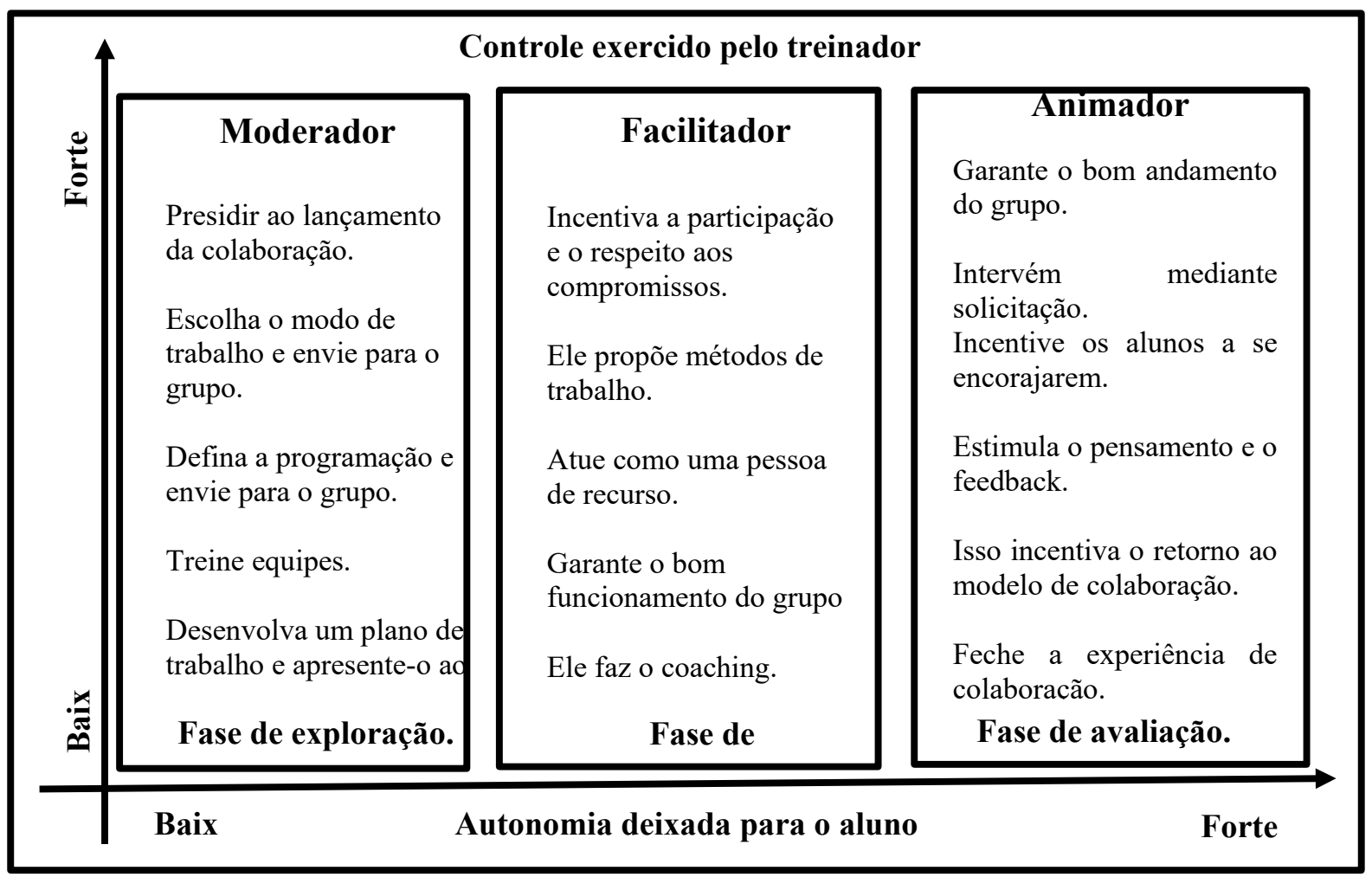

Garavit, J. 2021

Em cada uma das três fases, você manterá o papel de avaliador, sempre preocupado em diagnosticar a situação, avaliar o que está acontecendo e como está acontecendo para intervir adequadamente como um verdadeiro companheiro. A evolução do papel do formador ao longo das três fases do processo colaborativo visa permitir ao aluno exercer um maior controlo, desenvolver a sua responsabilidade e autonomia relativamente à sua aprendizagem. Este último gradualmente se desvanece para se tornar um simples facilitador de trocas (Brown e Palincsar, 1987). A Figura 4.4 mostra como suas intervenções são moduladas de uma fase para outra.

\section{Avaliação de treinamento}

Durante um treinamento a distância na modalidade virtual, a aprendizagem é numerosa e de vários tipos: cognitiva, psicossocial, metodológica e tecnológica. No coletivo das disciplinas, não é necessário avaliar todas essas aprendizagens. Geralmente, buscamos principalmente medir a aprendizagem cognitiva. Mas na abordagem colaborativa, a avaliação da aprendizagem também deve estar relacionada ao processo colaborativo.

\section{Avaliação do treinamento cognitivo}

A liberdade que os alunos têm no processo colaborativo e a personalização do seu modelo de conhecimento colocam sérios problemas para os avaliadores quando têm que se certificar de 
que ao final de um curso de formação os alunos possuem essa ou aquela habilidade. Não existem soluções prontas para o problema de avaliação e monitoramento da qualidade da aprendizagem. Jonassen (1995), entretanto, abre caminhos interessantes para nós por meio de seu trabalho sobre a avaliação de modelos mentais.

\section{Avaliação dos modelos intelectuais dos alunos}

Mencionamos no início deste trabalho que a abordagem colaborativa é aquela que serve à construção de um conhecimento complexo, denominado avançado, melhor do que qualquer outro, por meio da transferência de conhecimento e da valorização de situações complexas ou retrocessos. A resolução de problemas é uma habilidade altamente valorizada na sociedade; é prerrogativa do pensamento humano. É por isso que Jonassen se propõe a focar o treinamento na resolução de problemas classificados como complexos, pois exigirão a aplicação não de um, mas de vários sistemas de conhecimento.

¿Mas, no final de um treinamento, como saber se o aluno alcançou conhecimento suficiente para resolver problemas complexos reais? Como avaliar seu aprendizado? Uma das formas de proceder seria avaliar as representações mentais que o aprendiz usa para resolver, em contexto, um problema mal ou mal estruturado. Para saber se o conhecimento construído pelo aluno é completo e se ele pode transferi-lo, é necessário primeiro entender o modelo mental que ele desenvolveu, para depois avaliá-lo. O desempenho de um aluno pode ser explicado, pelo menos em parte, pela qualidade dos modelos mentais que ele possui e sabe aplicar para resolver problemas (Gott, Benett e Gillet, 1988, citado por Jonassen, 1995).

\section{O que é e como são avaliados os modelos mentais?}

A teoria dos modelos mentais tenta explicar o fenômeno da compreensão em humanos. Essa compreensão resulta em modelos que fornecem representações que, por sua vez, fornecem um meio para interpretar, memorizar e comunicar informações e monitorar o desempenho (Wild, 1996). Os modelos mentais correspondem às concepções que cada pessoa desenvolve em seu universo mental na forma de representações de objetos ou eventos e de relações estruturais entre esses objetos ou eventos.

Portanto, os modelos mentais são feitos de objetos e relacionamentos. Esses objetos são conceitos (nós) e suas relações são ligações (verbos que estabelecem a natureza das ligações entre os objetos (Jonassen, 1995). O resultado é uma rede ou mapa de relações que descreve a área de conhecimento representada pelo mental modelo Os modelos mentais descrevem como todos concebem um domínio. Eles variam de uma pessoa para outra com base em instruções anteriores, habilidades individuais, crenças e princípios adquiridos. Construídos com raciocínio analógico e metafórico, podem ser descritos da seguinte forma: 
- São representações internas que cada um desenvolve.

- A linguagem é a chave para compreender os modelos mentais; eles são o assunto da cobertura da mídia linguística.

- Eles podem ser representados por redes conceituais.

- O significado dado aos conceitos é compreendido em sua relação com outros conceitos.

- O significado social atribuído aos conceitos surge da intersecção dos diferentes modelos mentais encontrados em todos (Carley e Palmquist, citados por Jonassen, 1995).

Jonassen acrescenta que os modelos mentais são construções dinâmicas, multimodais e multidimensionais. São complexos e epistêmicos, ou seja, são uma forma de expressar como sabemos o que sabemos. Eles não são facilmente compreendidos pelos outros e é por isso que devem ser inferidos pela manifestação de uma performance. O desempenho que traduz um modelo mental é composto por vários tipos de conhecimento que podem ser avaliados. Jonassen preserva:

- Conhecimento estrutural: compreensão da organização de uma influência ou domínio.

- Conhecimento processual de execução: capacidade de resolução de um problema.

- Conhecimento processual de reflexão: a capacidade de ensinar outra pessoa a fazê-lo.

- A imagem do sistema: capacidade de desenvolver imagens mentais.

- A metáfora: capacidade de vincular o sistema estudado a um sistema existente.

- Conhecimento executivo: a capacidade de usar o modelo mental correto no momento certo (um problema complexo requer o uso de vários modelos mentais).

Tabela 4.6

Avaliação de modelos mentais

\begin{tabular}{|l|l|}
\hline \multicolumn{1}{|c|}{ Critérios de avaliação } & \multicolumn{1}{c|}{ Estratégia de avaliação } \\
\hline 1. Consistência. & Pense em voz alta (para obter uma visão estrutural). \\
\hline 2. Relevância pessoal. & Relatório cognitivo, entrevista cognitiva. \\
\hline 3. Integração. & Simulação cognitiva. \\
\hline 4. Fidelidade à realidade. & Comparação com o modelo do especialista. \\
\hline 5. Imagens. & Geração de metáforas e analogias. \\
\hline 6. Complexidade. & Pense em voz alta (para obter uma visão estrutural). \\
\hline 7. Aplicabilidade, transferibilidade. & Ensine outro, pense em voz alta. \\
\hline 8. Inferência & Usando o modelo certo na hora certa. \\
\hline
\end{tabular}

\section{Garavit, J. 2021}

Os modelos mentais podem ser avaliados a partir de oito critérios: coerência, relevância, integração pessoal, fidelidade à realidade, imagética, complexidade, transferibilidade, inferência, usando meios baseados na verbalização. Resumimos, na Tabela 4.6, o modelo de avaliação desenvolvido por Jonassen. 


\section{Preços de abordagem colaborativa}

A avaliação da aprendizagem de uma perspectiva cognitivista é um procedimento complexo. Os testes de memorização frequentemente usados na educação não fornecem uma medida de aprendizagem em toda a sua complexidade. Do ponto de vista da abordagem colaborativa, a avaliação da aprendizagem engloba o desempenho cognitivo e a capacidade de colaboração. $\mathrm{O}$ primeiro pode ser avaliado, como sugere Jonassen, analisando as produções dos alunos e o segundo será avaliado pela observação do comportamento e análise das percepções. Podem ser utilizadas três formas de avaliação, avaliação diagnóstica, avaliação formativa e avaliação somativa, nas diferentes etapas (ver Tabela 4.7). Nós os resumimos usando as definições fornecidas por Legendre (1993).

Tabela 4.7

\section{Critérios de avaliação}

\begin{tabular}{|c|c|c|}
\hline $\begin{array}{c}\text { Avaliação nas três fases de } \\
\text { colaboração }\end{array}$ & $\begin{array}{l}\text { Critérios de avaliação } \\
\text { cognitiva com base nas } \\
\text { produções do aluno }\end{array}$ & $\begin{array}{l}\text { Critérios para avaliar a capacidade } \\
\text { de colaboração }\end{array}$ \\
\hline $\begin{array}{l}\text { Fase de exploração } \\
\text { Avaliação-diagnóstico } \\
\text { Objetivo: valorizar as características } \\
\text { individuais que podem ter influências } \\
\text { positivas ou negativas na } \\
\text { aprendizagem. }\end{array}$ & $\begin{array}{l}\text { - Informar o modelo de } \\
\text { conhecimento } \\
\text { especialista. }\end{array}$ & $\begin{array}{l}\text { Medidas tomadas desde o início: } \\
\text { - Grau de autonomia. } \\
\text { - Habilidades sociais. } \\
\text { - Experiências de colaboração. } \\
\text { - Percepções de colaboração. } \\
\text { - Competências metodológicas. } \\
\text { - Competências tecnológicas. }\end{array}$ \\
\hline $\begin{array}{l}\text { Fases de desenvolvimento e } \\
\text { avaliação } \\
\text { Teste formativo } \\
\text { Objetivo: informar ao aluno os } \\
\text { objetivos alcançados ou não para } \\
\text { fornecer o suporte necessário. }\end{array}$ & $\begin{array}{l}\text { - Os conceitos } \\
\text { - A estrutura e as ligações } \\
\text { entre os conceitos. } \\
\text { - Clareza de representação. } \\
\text { - Relevância. }\end{array}$ & $\begin{array}{l}\text { Inventário de percepções relacionadas } \\
\text { à produtividade do grupo: } \\
\text { - O uso do tempo. } \\
\text { - O desenvolvimento de ideias. } \\
\text { - Tomar decisões. } \\
\text { - Comportamento do grupo. } \\
\text { - A realização do grupo. }\end{array}$ \\
\hline $\begin{array}{l}\text { Fase de avaliação } \\
\text { Avaliação somativa } \\
\text { Objetivo: fazer um juízo sobre o grau } \\
\text { de aproveitamento da aprendizagem } \\
\text { para decidir sobre a promoção, o } \\
\text { credenciamento ou a concessão de um } \\
\text { diploma. }\end{array}$ & $\begin{array}{l}\text { - Aplicabilidade. } \\
\text { - Transferibilidade. }\end{array}$ & $\begin{array}{l}\text { Participação qualificada de acordo } \\
\text { com: } \\
\text { - A regularidade das contribuições, } \\
\text { - Respeito pelo contrato e pelo } \\
\text { cronograma negociado e acordado } \\
\text { pelo grupo / equipe. }\end{array}$ \\
\hline
\end{tabular}

Garavit, J. 2021

A avaliação-diagnóstico é aplicada sobretudo no início da colaboração, antes de os alunos iniciarem o processo. Abrange conhecimentos relacionados ao objeto de aprendizagem, habilidades e conhecimentos relacionados ao trabalho colaborativo e habilidades técnicas relacionadas ao uso do ambiente de aprendizagem. Os resultados são usados para ajudar o treinador a avaliar se os alunos estão prontos para participar e têm o conhecimento, as habilidades ou as habilidades para colaborar. Eles permitem antecipar as dificuldades do progresso e, se necessário, propor medidas para superá-las. 
A avaliação formativa ocorre principalmente na segunda e terceira fase da colaboração. Seu objetivo é fornecer informações contínuas sobre as dificuldades vividas e os avanços obtidos. Destina-se principalmente a ajudar o aluno e o grupo, mas também pode ser utilizado como elemento de motivação extrínseca para o aluno e como índice de produtividade para o grupo. A avaliação formativa consegue ser elaborada pelo formador ou pelos colegas. A avaliação somativa ocorre na terceira fase, ao final do treinamento; é assegurado pelo formador, que faz um juízo sobre o grau de realização da aprendizagem. Além de utilizar o aproveitamento dos alunos como evidência da formação, a avaliação é feita com base na avaliação estabelecida pelos alunos para encerrar a colaboração.

\section{Deduções}

Na nossa vida pessoal e profissional, prestamo-nos à colaboração sem estar sempre cientes disso. Demonstramos nosso compromisso tomando ações que ajudam a atingir uma meta que compartilhamos com outras pessoas. Algumas pessoas são mais propensas do que outras a colaborar. Colaboração, para eles, é uma filosofia ou um estilo de vida que os leva a integrar facilmente as interações sociais e cognitivas, assim como tudo o que vem do pertencimento a um grupo. Desde o início, eles percebem o significado do compromisso e da colaboração. Nele eles encontram realização, satisfação e gratificação. Além disso, outras pessoas percebem as abordagens, interações e negociações grupais inerentes à colaboração como restritivas, como obstáculos ao seu progresso.

A vontade de colaborar varia de pessoa para pessoa com base no perfil da personalidade, valores e experiências anteriores. Existem também outros fatores imediatos, como o contexto, o objetivo perseguido, as ações envolvidas, os problemas, etc. Nos grupos de treinamento, como em outros ambientes, os alunos têm atitudes diferentes em relação à colaboração. Então nos perguntamos como lidar com essa diversidade. Mas antes de responder a esta pergunta, devemos decidir sobre a experiência de colaboração. Você tem que saber se deve fazer parte do treinamento, por que e com que finalidade.

O treinamento não tem como objetivo principal preparar os trabalhadores para atender às necessidades do mercado. Seu objetivo é antes formar cidadãos que, juntos, possam contribuir para o desenvolvimento da sociedade. É em nome dos valores sociais e do crescimento pessoal que os educadores e formadores valorizam na formação colaborativa.

Adotar a colaboração como objetivo e como meio de formação não significa escolher o fácil. É uma escolha exigente e quem a faz merece a nossa admiração. Como vimos durante esta pesquisa, a abordagem colaborativa requer ir além do aluno e do treinador. Convida a mobilização genuína e abertura para os outros; é feito de concessões e uma certa renúncia para atingir a meta.

As situações colaborativas podem ser vivenciadas com dificuldade, ou mesmo com irritação por parte dos alunos dependendo se estão mais ou menos bem preparados, explicados e integrados na formação, de acordo com o tempo e recursos disponíveis, de acordo com o desejo 
de cada um. um deles. assumir o desafio de trabalhar juntos para aprender. Portanto, várias condições devem ser atendidas para que a colaboração seja possível. Tentamos identificá-los e descrevê-los na esperança de facilitar a prática colaborativa e promover seu sucesso.

O desafio que nos parece o mais importante a enfrentar é poder desenhar e conduzir o processo colaborativo com a preocupação pelo respeito de todos e a busca pelo bem de todos. Este paradoxo sempre existirá na colaboração que o reconhece ao propor uma estrutura flexível e adaptável. Ao contrário da cooperação, que oferece uma estrutura pré-definida, a colaboração, por meio de uma abordagem negociada, permite a todos medir, definir e comunicar o seu compromisso. Todos são convidados a dizer até onde querem ou até onde podem ir. Para lidar com tal situação, é importante que o grupo seja capaz de negociar maneiras de trabalhar em conjunto para criar uma situação viável e ideal.

A colaboração está cada vez mais presente na formação. Todos os programas de formação universitária, principalmente através da resolução de problemas ou da implementação de projetos, dão-lhe um lugar muito importante.A transição de uma lógica de ensino para uma lógica de aprendizagem exigiu, em todos os casos, uma reflexão profunda que deu lugar ao surgimento de um novo espírito de formação.

Nós nos perguntamos o que é treinamento; Para responder a essa pergunta, tivemos que repensar o aprendizado. Atualmente, o desejo de integrar o uso de novas tecnologias na formação, seja na formação empresarial ou universitária, deve ser acompanhado por uma redefinição de formação e aprendizagem. Esta redefinição deve, portanto, levar a uma reflexão sobre as potencialidades e limites das tecnologias de acordo com os objetivos perseguidos e a nova concepção de aprendizagem que teremos desenvolvido.

Queríamos alimentar esta reflexão associando em particular a abordagem construtivista à abordagem colaborativa. A pedagogia resultante desta associação está enraizada na comunidade e utiliza cenários pedagógicos baseados em situações e problemas reais. Esses cenários, procedendo de acordo com um processo de exploração, desenvolvimento e validação de conhecimento, enquadram o treinamento colaborativo que descrevemos como um processo conversacional onde os pares desempenham um papel importante junto com o treinador e o especialista em conteúdo.

Também propusemos o uso de tecnologias não apenas para permitir que os alunos realizem esse processo remotamente, mas porque essas novas ferramentas podem representar um suporte eficaz para a colaboração (comunicação, engajamento e coordenação). O uso das tecnologias que oferecemos nos permite afirmar nossa concepção de aprendizagem.

Estamos cientes de que a utilização de novos meios tecnológicos não conduz automaticamente à inovação educacional. Muitas vezes, os padrões herdados se infiltram insidiosamente no que pensamos ser novo e percebemos que, sob um dispositivo considerado de ponta, os velhos paradigmas se aplicam e as mesmas estruturas se aplicam. Sabendo que mudanças reais na pedagogia ainda são difíceis de implementar, esperamos que este trabalho 
possa contribuir para um novo exame do ato docente e para a descoberta do potencial das tecnologias para melhorá-lo. Também queremos que aqueles que fazem este exercício tenham cuidado para evitar a armadilha de mudanças superficiais que mascaram modelos antigos e lhes dão uma aparência de renovação. 


\section{Referências}

Appelt, W. (1995). Ferramentas interoperáveis para apoiar a cooperação usando a World-WideWeb. Centro Nacional Alemão de Pesquisa de Informação. Instituto Tecnológico de Tecnologia da Informação Aplicada.

Baffrey-Dumont, V. (2000). Pensamento pós-formal, julgamento reflexivo e pensamento reflexivo. In Pallascio, R. e Lafortune., L. Por um pensamento reflexivo em educação. Quebec University Press.

Berge, Z. (1995). Facilitação de conferências por computador: recomendações de campo. Tecnologia Educacional. vol.35, no 1.

Boder, A. (1993). O just in time do conhecimento nas organizações. In Proceedings of the IV International Colloquium on Cognitive Informatics of Organizations (ICO '93). Montreal, 4 a 7 de maio.

Brown, AL e Palincsar, AS (1987). Aprendizagem orientada, cooperativa e aquisição de conhecimentos individuais. Dans Resnick, LB, Cognição e instrução: problemas e agendas. Hillsdale, NJ, Erlbaum.

Chan, T.- W. e Chou, C.-Y. (novecentos e noventa e cinco). Simule um parceiro de aprendizagem em sistemas de tutoria recíproca.

Choi, J.-I. e Hanaafin, M. (1995). Aprendizagem situada: funções, estruturas e implicações para o design. ETR \& D, vol. 43, $n^{\circ} 2$.

Daniel, M.-F., Lafortune, L., Pallascio, R. e Scheffer, M. (2000). Comunidade de Pesquisa Filosófica. Em Pallascio, R. e Lafortune, L., Para o pensamento reflexivo na educação. Quebec University Press.

Damphousse, L. (1996). Participação e facilitação: um modelo para a análise da teleconferência assistida por computador na Teleuniversidade. Dissertação de mestrado em comunicação,

Feenberg, A. (1989). O mundo escrito. Mindweave, comunicação. Informática e Educação a Distância. Por dentro de Robin Mason e Anthony Kaye, Oxford, Reino Unido, Pergamon Press.

Garavit, J. (2021 g). Sistemas Processuais em Métodos de Ensino e Aprendizagem. https://doi.org/10.35542/osf.io/5n6kv

Jonassen, DH (1995). Operacionalização de modelos mentais: estratégias para avaliar modelos mentais para apoiar a aprendizagem significativa e ambientes de aprendizagem que apoiam o design. Nova york.

Legendre, R. (1993). Dicionário Atual de Educação. 2a ed., Paris, Montreal, Larousse.

Lundgren, K. (1996). Conferência por Computador: Um Ambiente de Aprendizagem Colaborativa para Alunos de Educação a Distância. Tese de doutorado, Montreal, University. Concórdia.

Martineau, R. (2000). O pensamento histórico, uma alternativa valiosa de reflexão para a formação do cidadão. In Pallascio, R. e Lafortune, L., Para um pensamento reflexivo em educação.

Pallascio, R. e Lafortune, L., (2000). Para o pensamento reflexivo em educação. Quebec University Press. 
Paquin, C., Paquette, G., Bourdeau, J. e Rigault, C. (1996). Especificação de requisitos. Arquitetura do Campus Virtual. Relatório interno do projeto Hyper Guide e Recto. Montreal, Centro de Pesquisa LICEF.

Reid, JA., Forrestal, P. e Cook, J. (1989). Aprendizagem em pequenos grupos em sala de aula. Toronto, Irwin Publications.

Ricciardi Rigault, C. et al. (1993). Aprendizagem colaborativa e teleconferência assistida de forma inteligente. Relatório de investigação apresentado ao CRIM. Montreal, centro de pesquisa LICEF, Universidade Tele.

Romainville, M. (2000). Saber aprender é suficiente para aprender melhor? Melhorias na metacognição e desempenho. In Pallascio, R. e Lafortune, L., Para um pensamento reflexivo em educação.

Tagg, AC (1994). liderança de dentro: moderação de alunos em conferências por computador. The American Journal of Distance Education, vol. 8, $\mathrm{n}^{\circ} 3$.

Wenger, E. e Lave, J. (1991). Situado em Aprendizagem: Cambridge, Cambridge University Press.

Wild, M. (1996). Modelos mentais e modelagem computacional. Journal of Computer Aided Learning, vol. 12 